\title{
Temporal Trends of the Clinical, Resource Use and Outcome Attributes of ICU-Managed Candidemia Hospitalizations: A Population-Level Analysis
}

\author{
Lavi Oud
}

\begin{abstract}
Background: There are mixed findings on the longitudinal patterns of the incidence of intensive care unit (ICU)-managed candidemia, with scarcity of reports on the corresponding evolving patterns of patients' clinical characteristics and outcomes. No population-level data were reported on the temporal trends of the attributes, care and outcomes of ICU-managed adults with candidemia.
\end{abstract}

Methods: The Texas Inpatient Public Use Data File was used to identify hospitalizations aged 18 years or older with a diagnosis of candidemia and ICU admission (C-ICU hospitalizations) between 2001 and 2010. Temporal trends of the demographics, clinical features, use of healthcare resources, and short-term outcomes were examined. Average annual percent changes (AAPCs) were derived.

Results: C-ICU hospitalizations $(\mathrm{n}=7,552)$ became (AAPC) increasingly younger (age $\geq 65$ years: $-1.0 \% /$ year). The Charslon comorbidity index rose $4.2 \% / y e a r$, while the mean number of organ failures (OFs) increased by $8.2 \% / y e a r$, with a fast rise in the rate of those developing $\geq 3$ OFs (+15.5\%/year). Between 2001 and 2010, there was no significant change in utilization of mechanical ventilation and new hemodialysis among C-ICU hospitalizations with reported respiratory and renal failures $(68.9 \%$ vs. $73.3 \%, \mathrm{P}=0.3653$ and $15.5 \%$ vs. $21.8 \%, \mathrm{P}=0.8589$, respectively). Hospital length of stay or total hospital charges remained unchanged during study period. Hospital mortality decreased between 2001 and 2010 from $39.3 \%$ to $23.8 \%$ (-5.2\%/year). The majority of hospital survivors $(61.6 \%)$ were discharged to another facility, and increasingly to long-term acute care hospitals, with routine home discharge decreasing to $11 \%$ by 2010 .

Conclusions: C-ICU hospitalizations demonstrated increasing comorbidity burden and rising development of OF, and matching rise in use of selected life-support interventions, though with unchanged in-hospital fiscal impact. There has been marked decrease in hospital mortality, but survivors had substantial residual morbidity with the

Manuscript accepted for publication February 10, 2016

Division of Pulmonary and Critical Care Medicine, Department of Internal Medicine, Texas Tech University Health Sciences Center at the Permian Basin, 701 W. 5th St., Odessa, TX 79763, USA.Email: lavi.oud@ttuhsc.edu

doi: http://dx.doi.org/10.14740/jocmr2484w majority discharged increasingly to another post-acute care facility.

Keywords: Candidemia; Intensive care unit; Mortality; Organ failure; Outcomes

\section{Introduction}

Candidemia remains among the most common causes of bloodstream infections [1] and according to a recent multistate hospital survey in the United States (US), candida species have become the most common isolates in healthcare-associated bloodstream infections [2]. Predisposing risk factors for candidemia are commonly present in critically ill patients [3] and candidemic patients can require intensive care unit (ICU) care due to resultant critical illness [4], with candidemia remaining associated with high case fatality among the critically ill [5-8].

Only few studies have examined contemporary trends of the incidence of candidemia in ICU-managed patients, showing mixed findings, with unchanged [9] or a mix of rising with either preceding [8] or subsequently [10] plateauing incidence patterns. The sources of this variability are unclear. Data on the evolving patterns of the characteristics of critically ill candidemic patients can complement the observed epidemiological trends and may inform clinical practice and future studies of preventive and therapeutic interventions in this population.

However, although numerous studies have characterized critically ill candidemic patients, their care, and outcomes [4$6]$, there have been scarce data $[7,8]$ on the corresponding longitudinal patterns of these attributes.

We sought to examine the population-level temporal trends of the demographic, clinical, resource use, and shortterm outcome characteristics of ICU-managed candidemic patients in Texas.

\section{Materials and Methods}

\section{Setting and data sources}

The Texas Inpatient Public Use Data File (TIPUDF) was used to perform a retrospective, population-based cohort study of 
ICU-managed adult state residents with a diagnosis of candidemia. The TIPUDF is an administrative dataset maintained by the Texas Department of State Health Services [11]. The use of the dataset has been previously described [12]. Briefly, TIPUDF includes detailed de-identified inpatient discharge data on the demographic, clinical, resource utilization, and outcome domains from state-licensed hospitals, and captures $93-97 \%$ of all hospital discharges in the state. The Institutional Review Board of Texas Tech Health Sciences Center has determined that the present study is exempt from formal review due to use of publicly available, de-identified data.

\section{Study population}

We identified hospitalizations aged 18 years or older with a reported primary or secondary diagnosis of candidemia and with admission to ICU (termed C-ICU hospitalizations in the remainder of the manuscript) during the years $2001-2010$. A diagnosis of candidemia was based on reported International Classification of Diseases, Ninth Revision, Clinical Modification (ICD-9-CM) code 112.5 [13, 14]. An admission to ICU was defined as presence of an ICU charge greater than $\$ 0$.

\section{Data collection}

We collected data on patients' age, gender, race/ethnicity (categorized as non-Hispanic black (black), non-Hispanic white (white), Hispanic, and other), comorbid conditions (based on the Deyo modification of the Charlson comorbidity index [15]), medical or surgical hospitalization (based on diagnosisrelated groups), type and number of failing organs $[16,17]$ (Supplementary Table 1, www.jocmr.org), life-support interventions (mechanical ventilation, central venous catheterization, and new hemodialysis; new hemodialysis was defined as a combination of a hemodialysis code and a code for acute renal failure) (Supplementary Table 2, www.jocmr.org), hospital length of stay, total hospital charges, and discharge disposition at the end of hospitalization. The categories of patients' discharge disposition were grouped as death, hospice, home (with and without home health), another hospital, nursing facility, and other (leave against medical advice and unknown). Given the increasing use of hospice in severely ill hospitalized patients [17], those ending with death or discharge to hospice were further grouped as end-of-life (EOL) hospitalizations. Because patients with chronic critical illness are increasingly discharged to long-term acute care hospitals [18], we further examined use of these facilities among patients discharged to another hospital. Discharge destination (excluding EOL hospitalizations) was used as proxy of residual morbidity. Changes in the number of failing organs were used as a surrogate measure for severity of illness [17].

\section{Data analysis}

Because TIPUDF provides discharge-level, rather than pa-
Table 1. The Demographics and Health Insurance Characteristics of C-ICU Hospitalizations, 2001 - 2010

\begin{tabular}{|ll}
\hline Group & $\mathbf{n}=\mathbf{7 , 5 5 2}$ \\
\hline Age $($ years $), \mathrm{n}(\%)^{\mathrm{a}}$ & \\
\hline $18-44$ & $1,177(15.6)$ \\
$45-64$ & $2,774(36.7)$ \\
$\geq 65$ & $3,601(47.7)$ \\
\hline Male, $\mathrm{n}(\%)^{\mathrm{a}, \mathrm{b}}$ & $3,242(46.5)$ \\
\hline Race/ethnicity, $\mathrm{n}(\%)^{\mathrm{a}}$ & \\
\hline White & $3,840(50.8)$ \\
\hline Hispanic & $1,590(21.1)$ \\
\hline Black & $1,512(20.0)$ \\
\hline Other & $591(7.8)$ \\
\hline Missing & $1(0.3)$ \\
\hline Health insurance, $\mathrm{n}(\%)^{\mathrm{a}}$ & \\
\hline Private & $1,973(26.1)$ \\
\hline Medicare & $4,212(55.8)$ \\
\hline Medicaid & $770(10.2)$ \\
\hline Uninsured & $478(6.3)$ \\
Other & $118(1.6)$ \\
Missing & $1(0.3)$ \\
\hline
\end{tabular}

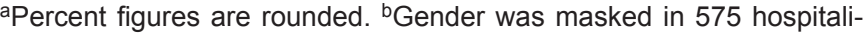
zations. The denominator used to derive gender percentages for the cohort was based on hospitalizations with available gender designation $(n=6,977)$.

tient-level information, we reported identified ICU-managed events as number of hospitalizations.

The state of Texas masks gender data of hospitalizations with a diagnosis of infection with the human immunodeficiency virus (HIV), ethanol or drug abuse. Thus, analyses involving gender were restricted to hospitalizations without the aforementioned three diagnoses.

Because changes in the frequency of reported organ failures (OFs) over time may represent over-coding [16], we compared the rates of utilization of organ-specific life-support interventions among C-ICU hospitalizations with a specific OF (i.e., use of mechanical ventilation among hospitalizations with reported respiratory failure) at the start and end of study period.

Linear regression analyses of log-transformed data were used to examine the temporal trends of examined demographics, clinical attributes, use of healthcare resources, and outcomes, and to derive a corresponding relative average annual percent change (AAPC), using mean, median, and percentage data of the examined domains. Total hospital charges were adjusted to the consumer price index [19] (2010 dollars).

Group data are reported as numbers (percentages) for categorical variables and mean (standard deviation (SD)) or median (interquartile range (IQR)) for continuous variables, as appropriate. $\mathrm{X}^{2}$ tests were used to compare categorical data. Ninety-five percent confidence intervals (95\% CIs) were cal- 
Table 2. Select Demographic Characteristics, Health Insurance, and Comorbidities of C-ICU Hospitalizations, 2001 - 2010

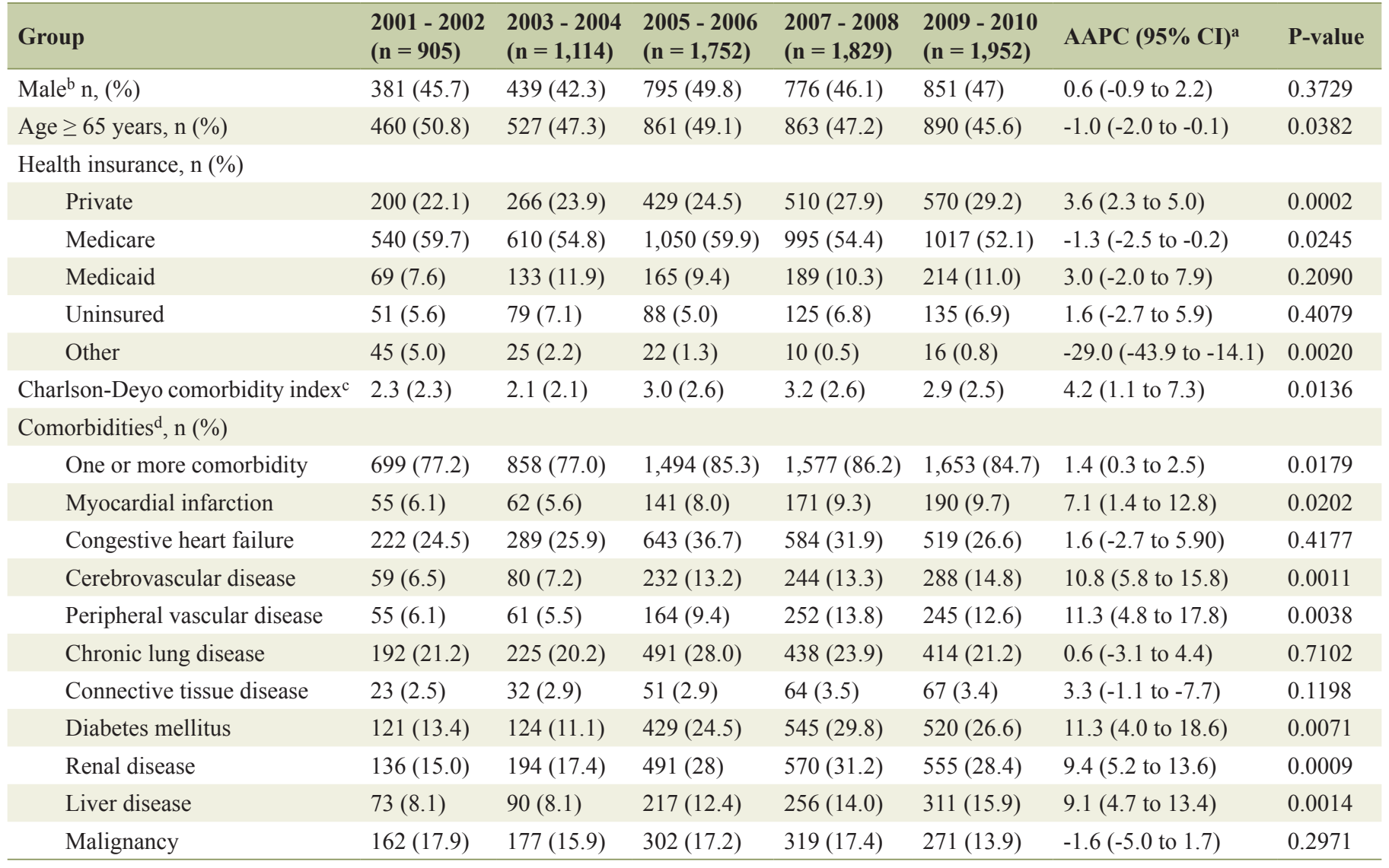

aAAPC: average annual percent change (95\% confidence intervals). ${ }^{\mathrm{b}}$ The denominator used to derive male percentage for the cohort was based on hospitalizations with available gender designation. ${ }^{\mathrm{C}}$ Mean (standard deviation). ${ }^{\mathrm{d} B a s e d}$ on the Charlson-Deyo comorbidity index.

culated. We used SAS version 9.3 (SAS Institute, Cary, NC, USA) and MedCalc version 15.6 (MedCalc Software, Ostend, Belgium) software for data analyses. A two-sided $\mathrm{P}$ value $<$ 0.05 was considered significant.

\section{Results}

There were 7,552 C-ICU hospitalizations during study period. Details of the demographic characteristics and health insurance are outlined in Table 1. In addition, trends of use of various categories of health insurance are detailed in Table 2. Health insurance data were missing in one hospitalization. C-ICU hospitalizations became increasingly (AAPC $(95 \% \mathrm{CI})$ ) younger (age $\geq 65$ years: $-1 \%$ year $(-2.0 \%$ to $-0.1 \%)$ ), while their gender and race/ethnicity composition remained unchanged (data not shown). Medicare was the most common form of health insurance for the whole cohort and was used in $29.8 \%$ of CICU hospitalizations younger than 65 years. The health insurance used among $\mathrm{C}$-ICU hospitalizations has changed between 2001 and 2010, with decreased use of Medicare (-12\%) and marked rise in use of private insurance $(+31 \%)$.

Comorbid conditions were reported in the majority of $\mathrm{C}$ ICU hospitalizations (Table 2), and were increasingly present, with the mean (SD) Charlson-Deyo comorbidity index rising $4.2 \%$ /year (1.1-7.3\%). Congestive heart failure and renal disease were the most commonly reported conditions among examined comorbidities, with the fastest growth from 2001 to 2010 noted in renal failure $(123 \%)$ and cerebrovascular disease (114\%). HIV infection was rarely reported (132 (1.7\%) hospitalizations). Surgical C-ICU hospitalizations $(n=4,042$, $53.5 \%)$ progressively decreased $(-1.4 \% /$ year $(-2.1 \%$ to $-0.7 \%)$ ) over study period.

The patterns of $\mathrm{OF}$ and used healthcare resources are detailed in Table 3. The mean number of failing organs rose $8.1 \%$ year (5.2-10.9\%), with the growth rate of those with $\geq$ 3 organ failures increasing $15.5 \%$ year (9.2-21.7\%). The rates of all examined OFs increased over study period, with those affecting the respiratory, cardiovascular and renal systems remaining the most common. The fastest growth rate of individual OFs between 2001 and 2010 involved the neurological (469\%) and cardiovascular (215\%) systems.

The use of examined life-support interventions increased during study period (Table 3). The use of mechanical ventilation and new hemodialysis among those with specific OFs tended to rise but was not statistically different between 2001 and 2010: 1) mechanical ventilation: $68.9 \%$ vs. $73.3 \%(\mathrm{P}=$ 0.3653 ) among those with respiratory failure; 2) new hemodi- 


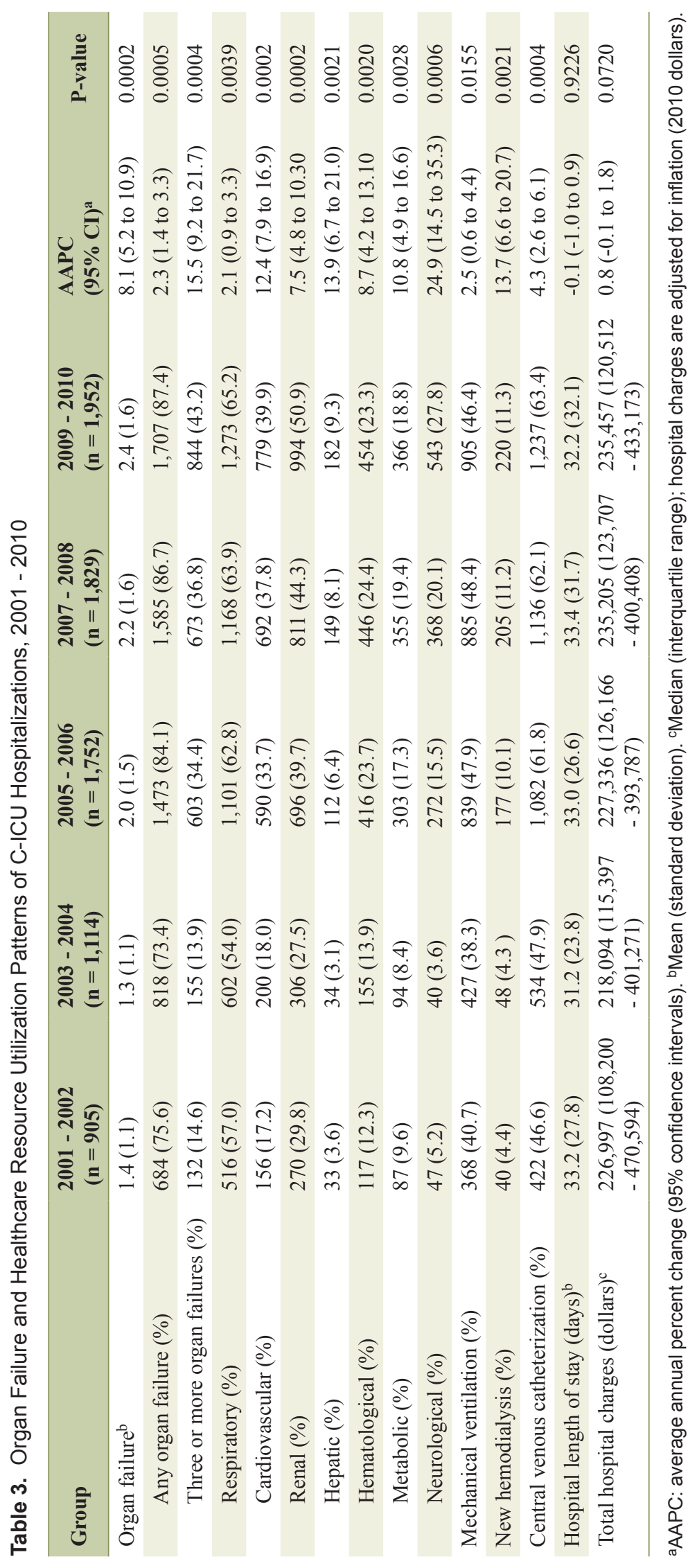


Table 4. Discharge Disposition of C-ICU Hospitalizations, 2001 - 2010

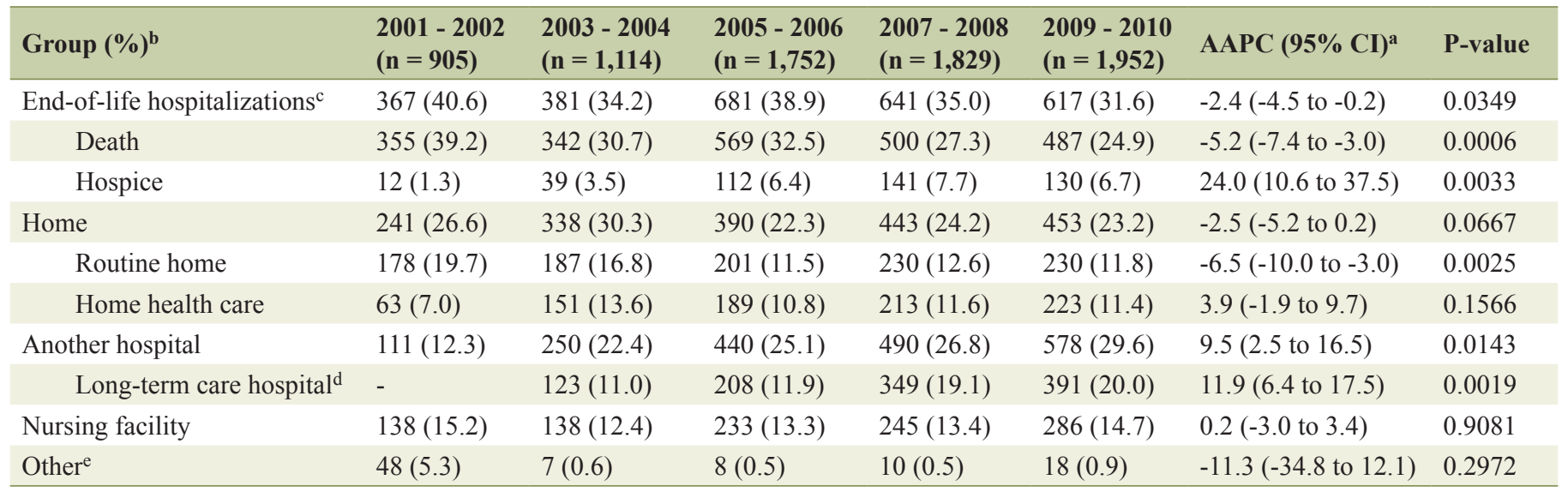

aAAPC: average annual percent change (95\% confidence interval). ${ }^{b}$ Percent figures are rounded. ${ }^{~}$ End-of-life hospitalizations were those with either hospital death or discharge to hospice. dExamination of annual changes was limited to the years $2003-2010$, as the first discharges to a long-term care facility were reported in 2003 . eLeave against medical advice and unknown discharge destination.

alysis: $15.5 \%$ vs. $21.8 \%(\mathrm{P}=0.8589)$ among those with acute renal failure. The mean (SD) hospital length of stay (32.7 (29.2) days) remained unchanged, while the median (IQR) total hospital charges $(\$ 231,141(120,093-416,028))$ tended to slowly rise (though not statistically significantly) during study period.

Discharge dispositions of C-ICU hospitalizations are detailed in Table 4. Hospital mortality was $29.8 \%$ for the whole cohort and decreased by $5.2 \% /$ year $(-7.4 \%$ to $-3.0 \%)$, while discharge to hospice rose $24 \%$ year (10.6-37.5\%). Among hospital survivors (excluding those discharged to hospice), $61.6 \%$ were discharged to another facility. Transfers to a long-term acute care hospital rose $11.9 \%$ year (6.4-17.5\%) since 2003, accounting for $20.9 \%$ of all discharges in 2010 . Routine home discharge declined by $6.5 \%$ year $(-10.0 \%$ to $-3.0 \%)$, reaching $11 \%$ of all discharges in 2010 .

\section{Discussion}

We found that over the last decade, there has been increasing burden of comorbidity, rising development of OF, and corresponding increased use of the examined life-support interventions among C-ICU hospitalizations. These trends were associated unexpectedly with substantial progressive decrease in hospital mortality. However, the majority of hospital survivors were discharged to another facility and there has been rapid increase in transfers to long-term acute care hospitals.

To our knowledge, the present study represents the first population-level examination of the temporal trends of the demographic, clinical, resource use, and outcome attributes of ICU-managed candidemic patients in the US, and the largest cohort to date in this population. Two recent studies of critically ill candidemic patients in Brazil [7] and France [8] have examined changes in patients attributes between two 4-year periods [7] and trends of annual 30-day mortality and antifungal therapy [8]. However, other multi-year ICU-focused studies of candidemia did not examine evolving patterns of patient attributes, likely in part due to challenges posed by relatively small cohort size $[6,20]$, thus affecting the interpretation of the present findings in the context of prior work.

Reported gender composition varied in prior studies [4-6, 14]. Our findings of female predominance among C-ICU hospitalizations are in agreement with a national population-based study in the US by Zaoutis and colleagues [14]. However, candidemic patients were mostly male in population-level studies in other countries $[21,22]$ and in reports on active surveillance registries in the US [23]. Although sepsis in general is considered to develop more commonly among males [24], the role of gender in development of candidemia requires further study.

$\mathrm{C}$-ICU hospitalizations have been increasingly younger, in contrast to an unchanged age composition in other studies [7, 8]. The sources of the discordant trends are unclear, but may be related to differences in population mix due to geographical variation and that between tertiary care hospitals and broader array of acute care facilities in a population-based study.

Black and Hispanic patients were represented among CICU hospitalizations in substantially higher and lower rates, respectively, as compared to their share in the adult population in Texas [25]. Our findings are in agreement with prior reports showing markedly higher rates of candidemia in black patients [3], and with the findings by Zaoutis and colleagues, showing that adult Hispanic patients are underrepresented as compared to their national population share in the US [14]. However, the impact of Hispanic ethnicity on development of candidemia in the US population has not been systematically examined [3] and Hispanic patients were often not considered as a specific group in US studies [23, 26, 27]. Nevertheless, a report by Barnatto and colleagues showed an adjusted lower risk of severe sepsis among Hispanics in the US [28]. However, as noted by the investigators, administrative population-level studies cannot distinguish between differences in biological susceptibility and residual cofounding [28].

The health insurance used by candidemic patients has not been previously reported, though risk of sepsis-associated hospitalizations and related mortality [29], as well as processes of 
care among critically patients [30] has been reported to vary in association with specific health insurance categories. Our finding that nearly one-third of C-ICU hospitalizations younger than 65 years had Medicare insurance further underscores the frequent occurrence of substantial comorbidity burden in this cohort. The marked decrease in use of Medicare insurance over time was likely, for the most part, due to near-similar absolute decrease in elderly C-ICU hospitalizations over the past decade. However, the sources of the predominant increase of C-ICU hospitalizations with private insurance vs. other alternatives are unclear.

The findings of the most prevalent comorbidities affecting C-ICU hospitalizations contrast with common reports of malignancy being the most common comorbidity and were reported at higher rates than in the present study [5, 6, 8, 27]. The sources of the difference are unclear, but may be related to common studies involving referral centers $[7,8,27]$ or academic hospitals [5]. In addition, previous studies provided at times limited data on categories of comorbid conditions [4, 6, $8]$, and occurrence of heart failure (the most common comorbidity in the present study) was rarely reported [27]. Similarly, the frequency of overall occurrence of comorbidities among candidemic critically ill patients was generally not described $[5-8,20,27]$. However, our finding that the majority of C-ICU hospitalizations had one or more of the examined comorbidities is in agreement with a recent study by Ylipalosaari and colleagues [4]. Finally, the increasing burden of comorbid conditions among $\mathrm{C}$-ICU hospitalizations in the present cohort likely reflects overall increasing occurrence of chronic illness in the US population [31] and among the critically ill [17, 32].

Data on individual OFs were reported infrequently in studies of critically ill candidemic patients [27, 33, 34], with the most commonly affected systems being respiratory, cardiovascular, and renal, similar to the present study. The substantial rise in the reported number of failing organs and rates of individual OFs may represent increased clinician awareness, better documentation, or possible over-coding [16], especially given the progressive decrease in hospital mortality in the present cohort. However, the aforementioned changes were associated with corresponding unchanged rates of use of system-specific life-support interventions (i.e., mechanical ventilation among hospitalizations with respiratory failure), coupled with increased discharge to hospice, decreased rates of routine home discharge, and rapid rise of transfers to longterm acute care hospitals. These findings suggest that the rising occurrence of OF may reflect actual increase in severity of illness in the present cohort. The causes of an actual rise in the number of failing organs among D-ICU hospitalizations are unclear, but may be related in part to the increasing burden of comorbidities, which has been reported to be associated with development of OF [35]. Our findings contrast those of a recent study by Colombo and colleagues, reporting statistically insignificant downtrends of severity of illness scores in critically ill candidemic patients [7]. The source of difference is unclear, but may be related in part to different population mix in different geographical areas [36], the noted restriction to tertiary centers, and to the mostly unchanged comorbidity burden in the latter study [7].

The findings of lengthy hospital stay among candidemic patients are in agreement with prior reports $[4,5,33]$. There have not been, to our knowledge, studies on the fiscal impact associated with candidemia in critically ill patients, though studies not restricted to ICU populations showed, as expected, substantial excess costs $[3,14]$. The total hospital charges in the present cohort make C-ICU hospitalizations the most expensive condition among hospitalizations in Texas [37].

The lack of significant change in hospital length of stay and total hospital charges among increasingly sick patients can imply marked improvement in care efficiencies. However, it is likely that there has been incremental shift of inpatient length of stay and fiscal burden in the present cohort to post-acute care facilities, as shown by the rapidly rising transfers to longterm acute care hospitals. These changes in discharge patterns reflect broader changes in the US, related to increasing fiscal pressures on short-term hospital [38].

Prior reports on short-term outcomes of ICU-managed candidemia focused on patients' mortality [4-8]. The present study complements and extends available data, showing prevalent adverse impact of candidemia on hospital survivors. Our findings suggest substantial and incremental residual morbidity of C-ICU hospitalizations, with only one in 10 having routine home discharge by 2010 , and with the majority discharged to another facility, with likely rising occurrence of chronic critical illness among hospital survivors, as evidenced by the noted incremental transfer to long-term acute care hospitals.

The present study describes the first substantial and progressive population-level decrease in hospital mortality and EOL hospitalizations of candidemic critically ill patients. These changes occurred despite an increasingly sick cohort and may reflect in part the impact of improving patient care [39]. Similar findings of decreasing hospital mortality among patients with rising burden of chronic illness and that of OF were described in with severe sepsis [17]. In addition, decreasing mortality in the present cohort was also likely related to both the increasingly younger C-ICU hospitalizations and rising use of private health insurance, as the latter was shown to be associated with the lowest risk of death, as compared to other sources of health insurance (or lack thereof) [29, 30]. Hospital mortality in the present cohort was overall lower than commonly reported mortality data in critically ill candidemic patients [4-8]. The difference may reflect in part reporting of mortality at a pre-specified day number (i.e., 30-day mortality) $[7,8]$, as well as international outcome variability among critically ill populations, related to differences in population mix and practice patterns $[5,36]$. However, part of the difference may be related to possibly sicker populations managed in tertiary $[7,8]$ and predominantly academic centers [5].

Nevertheless, it is likely that the favorable changes of inhospital death underestimate short-term mortality of C-ICU hospitalizations, with the former possibly biased by the rapid rise in transfers to long-term acute care hospitals, as a high rate of early death has been reported among the latter [18]. Similar concerns were raised about possible bias in findings of decreasing hospital morality among critically ill patients in the general population, considered by other investigators to be related in part to increasing shift of hospital deaths to postacute care facilities [32], in association with the noted fiscal pressures on US hospitals [38] and use of hospital mortality as 
a performance measure [40, 41].

Previous studies of changes in mortality of critically ill candidemic patients described mixed findings, with reported decreasing [7] and rising [8] 30-day mortality. The conflicting results are difficult to reconcile as, in contrast to the present study, the investigators reported no significant change in age $[7,8]$, most reported comorbidities, severity of illness scores [7], or "major characteristics" [8], and with both studies reporting increased use of echinocandins $[7,8]$. Our findings are in agreement with studies in the US that did not focus on ICU patients, showing large decreases in 30-day mortality in two metropolitan areas [23] and at a single-center setting [42]. However, in contrast to our study, there was decrease in the burden of comorbidities in one study [42] and drop in occurrence of malignancy in the other [23]. None of the aforementioned four studies provided data on non-mortality outcomes.

The study has several limitations. We used a retrospective design with its attendant limitations. In addition, administrative data provide limited clinical detail and we could not distinguish ICU-acquired vs. non-ICU acquired candidemia, though both patient categories were often described as a single group [5, 6, 27, 33]. However, population-level data can complement and transcend the well-described regional and local variability in available critical care resources [43], rates of ICU utilization [44, 45], processes of care [45, 46], organization [46], and discharge practices [40, 41], and thus can provide broader perspective on examined conditions.

Although we used similar ICD-9 code-based approach to that of other investigators $[13,14]$, it is possible that some hospitalizations have been misclassified. The sensitivity and specificity of the code for disseminated candidiasis in identifying candidemia in administrative datasets is unknown and it is possible that we underestimated the burden of candidemia [14]. However, it is unlikely that the classification limitations biased the observed temporal trends.

In addition, established severity of illness scores cannot be derived from administrative data and we used the number of failing organs as a surrogate measure of changes in severity of illness over time. However, similar approach was employed by other investigators [17], as the number of failing organs remains associated with incremental risk of death among critically ill patients $[17,47]$.

Because the state of Texas does not provide tools to convert hospital charges to costs, we reported hospital charges rather than costs of care, limiting comparisons with other cost data.

Finally, although we examined a cohort of C-ICU hospitalizations in a large state with a diverse population, the characteristics of patients admitted to ICU, the used resources, and short-term outcomes may vary across states and nationally.

In conclusion, over the past decade ICU-managed candidemic hospitalizations in Texas became increasingly sick, with rising burden of comorbidities and increasing severity of illness, and required substantial, though unchanged, use of health care resources. ICU-managed candidemia became progressively less fatal, though changes in short-term mortality may have been underestimated. Hospital survivors incurred increasing residual morbidity, with the majority transferred to other facilities, and only one in 10 had routine home discharge by 2010 . Additional studies in other populations and health- care environments are warranted to examine the contemporary changes among critically ill candidemic patients.

\section{Acknowledgement}

I would like to thank Phillip Watkins, MS, for his help with parts of data acquisition and management.

\section{Conflict of Interests}

The author declares that there is no conflict of interests regarding the publication of this paper.

\section{Grant Support}

None.

\section{References}

1. Wisplinghoff H, Bischoff T, Tallent SM, Seifert H, Wenzel RP, Edmond MB. Nosocomial bloodstream infections in US hospitals: analysis of 24,179 cases from a prospective nationwide surveillance study. Clin Infect Dis. 2004;39(3):309-317.

2. Magill SS, Edwards JR, Bamberg W, Beldavs ZG, Dumyati G, Kainer MA, Lynfield R, et al. Multistate point-prevalence survey of health care-associated infections. N Engl J Med. 2014;370(13):1198-1208.

3. Pfaller MA, Diekema DJ. Epidemiology of invasive candidiasis: a persistent public health problem. Clin Microbiol Rev. 2007;20(1):133-163.

4. Ylipalosaari P, Ala-Kokko TI, Karhu J, Koskela M, Laurila J, Ohtonen P, Syrjala H. Comparison of the epidemiology, risk factors, outcome and degree of organ failures of patients with candidemia acquired before or during ICU treatment. Crit Care. 2012;16(2):R62.

5. Kett DH, Azoulay E, Echeverria PM, Vincent JL. Candida bloodstream infections in intensive care units: analysis of the extended prevalence of infection in intensive care unit study. Crit Care Med. 2011;39(4):665-670.

6. Leroy O, Gangneux JP, Montravers P, Mira JP, Gouin F, Sollet JP, Carlet J, et al. Epidemiology, management, and risk factors for death of invasive Candida infections in critical care: a multicenter, prospective, observational study in France (2005-2006). Crit Care Med. 2009;37(5):1612-1618.

7. Colombo AL, Guimaraes T, Sukienik T, Pasqualotto AC, Andreotti R, Queiroz-Telles F, Nouer SA, et al. Prognostic factors and historical trends in the epidemiology of candidemia in critically ill patients: an analysis of five multicenter studies sequentially conducted over a 9-year period. Intensive Care Med. 2014;40(10):1489-1498.

8. Lortholary O, Renaudat C, Sitbon K, Madec Y, DenoeudNdam L, Wolff M, Fontanet A, et al. Worrisome trends 
in incidence and mortality of candidemia in intensive care units (Paris area, 2002-2010). Intensive Care Med. 2014;40(9):1303-1312.

9. Meyer E, Geffers C, Gastmeier P, Schwab F. No increase in primary nosocomial candidemia in 682 German intensive care units during 2006 to 2011. Euro Surveill. 2013;18(24).

10. Oud L. Secular Trends in Utilization of Critical Care Services Among Candidemia-Associated Hospitalizations: A Population-Based Cohort Study. J Clin Med Res. 2016;8(1):40-43.

11. Texas inpatient public use data file. Texas Department of State Health Services, Center for Health Statistics, Austin, Texas (online). Available at: http://www.dshs.state. tx.us/thcic/hospitals/Inpatientpudf.shtm. Accessed August 25, 2014.

12. Oud L, Watkins P. Contemporary trends of the epidemiology, clinical characteristics, and resource utilization of necrotizing fasciitis in Texas: a population-based cohort study. Crit Care Res Pract. 2015;2015:618067.

13. Zilberberg MD, Shorr AF, Kollef MH. Secular trends in candidemia-related hospitalization in the United States, 2000-2005. Infect Control Hosp Epidemiol. 2008;29(10):978-980.

14. Zaoutis TE, Argon J, Chu J, Berlin JA, Walsh TJ, Feudtner $\mathrm{C}$. The epidemiology and attributable outcomes of candidemia in adults and children hospitalized in the United States: a propensity analysis. Clin Infect Dis. 2005;41(9):1232-1239.

15. Deyo RA, Cherkin DC, Ciol MA. Adapting a clinical comorbidity index for use with ICD-9-CM administrative databases. J Clin Epidemiol. 1992;45(6):613-619.

16. Lagu T, Rothberg MB, Shieh MS, Pekow PS, Steingrub JS, Lindenauer PK. Hospitalizations, costs, and outcomes of severe sepsis in the United States 2003 to 2007. Crit Care Med. 2012;40(3):754-761.

17. Kumar G, Kumar N, Taneja A, Kaleekal T, Tarima S, McGinley E, Jimenez E, et al. Nationwide trends of severe sepsis in the 21st century (2000-2007). Chest. 2011;140(5):1223-1231.

18. Kahn JM, Benson NM, Appleby D, Carson SS, Iwashyna TJ. Long-term acute care hospital utilization after critical illness. JAMA. 2010;303(22):2253-2259.

19. Bureau of labor statistics. United States Department of Labor. Available at: http://www.bls.gov/bls/inflation.htm. Accessed August 5, 2015.

20. Bassetti M, Righi E, Ansaldi F, Merelli M, Trucchi C, De Pascale G, Diaz-Martin A, et al. A multicenter study of septic shock due to candidemia: outcomes and predictors of mortality. Intensive Care Med. 2014;40(6):839-845.

21. Arendrup MC, Dzajic E, Jensen RH, Johansen HK, Kjaeldgaard P, Knudsen JD, Kristensen L, et al. Epidemiological changes with potential implication for antifungal prescription recommendations for fungaemia: data from a nationwide fungaemia surveillance programme. Clin Microbiol Infect. 2013;19(8):E343-353.

22. Asmundsdottir LR, Erlendsdottir H, Gottfredsson M. Nationwide study of candidemia, antifungal use, and antifungal drug resistance in Iceland, 2000 to 2011. J Clin
Microbiol. 2013;51(3):841-848.

23. Cleveland AA, Farley MM, Harrison LH, Stein B, Hollick R, Lockhart SR, Magill SS, et al. Changes in incidence and antifungal drug resistance in candidemia: results from population-based laboratory surveillance in Atlanta and Baltimore, 2008-2011. Clin Infect Dis. 2012;55(10):1352-1361.

24. Martin GS, Mannino DM, Eaton S, Moss M. The epidemiology of sepsis in the United States from 1979 through 2000. N Engl J Med. 2003;348(16):1546-1554.

25. Texas population downloads. Center for health statistics. Texas department of state health services. Available at: https://www.dshs.state.tx.us/chs/popdat/downloads.shtm. Accessed March 5, 2015.

26. Kao AS, Brandt ME, Pruitt WR, Conn LA, Perkins BA, Stephens DS, Baughman WS, et al. The epidemiology of candidemia in two United States cities: results of a population-based active surveillance. Clin Infect Dis. 1999;29(5):1164-1170.

27. Kollef M, Micek S, Hampton N, Doherty JA, Kumar A. Septic shock attributed to Candida infection: importance of empiric therapy and source control. Clin Infect Dis. 2012;54(12):1739-1746.

28. Barnato AE, Alexander SL, Linde-Zwirble WT, Angus DC. Racial variation in the incidence, care, and outcomes of severe sepsis: analysis of population, patient, and hospital characteristics. Am J Respir Crit Care Med. 2008;177(3):279-284.

29. O'Brien JM, Jr., Lu B, Ali NA, Levine DA, Aberegg $\mathrm{SK}$, Lemeshow S. Insurance type and sepsis-associated hospitalizations and sepsis-associated mortality among US adults: a retrospective cohort study. Crit Care. 2011;15(3):R130.

30. Fowler RA, Noyahr LA, Thornton JD, Pinto R, Kahn JM, Adhikari NK, Dodek PM, et al. An official American Thoracic Society systematic review: the association between health insurance status and access, care delivery, and outcomes for patients who are critically ill. Am J Respir Crit Care Med. 2010;181(9):1003-1011.

31. Bodenheimer T, Chen E, Bennett HD. Confronting the growing burden of chronic disease: can the U.S. health care workforce do the job? Health Aff (Millwood). 2009;28(1):64-74.

32. Zimmerman JE, Kramer AA, Knaus WA. Changes in hospital mortality for United States intensive care unit admissions from 1988 to 2012. Crit Care. 2013;17(2):R81.

33. Blot SI, Vandewoude KH, Hoste EA, Colardyn FA. Effects of nosocomial candidemia on outcomes of critically ill patients. Am J Med. 2002;113(6):480-485.

34. Nunes CZ, Marra AR, Edmond MB, da Silva Victor E, Pereira CA. Time to blood culture positivity as a predictor of clinical outcome in patients with Candida albicans bloodstream infection. BMC Infect Dis. 2013;13:486.

35. Esper AM, Moss M, Lewis CA, Nisbet R, Mannino DM, Martin GS. The role of infection and comorbidity: Factors that influence disparities in sepsis. Crit Care Med. 2006;34(10):2576-2582.

36. Vincent JL, Marshall JC, Namendys-Silva SA, Francois B, Martin-Loeches I, Lipman J, Reinhart K, et al. As- 
sessment of the worldwide burden of critical illness: the intensive care over nations (ICON) audit. Lancet Respir Med. 2014;2(5):380-386.

37. Facts and figures: statistics on hospital-based care in Texas, 2009. Texas Health Care Information Collection. DSHS Publication \# E87-11648. Available at: http:// www.dshs.state.tx.us/thcic/publications/hospitals/statisticalreports.shtm. Accessed August 25, 2014.

38. White C. Cutting medicare hospital prices leads to a spillover reduction in hospital discharges for the nonelderly. Health Serv Res. 2014;49(5):1578-1595.

39. Stevenson EK, Rubenstein AR, Radin GT, Wiener RS, Walkey AJ. Two decades of mortality trends among patients with severe sepsis: a comparative meta-analysis*. Crit Care Med. 2014;42(3):625-631.

40. Vasilevskis EE, Kuzniewicz MW, Dean ML, Clay T, Vittinghoff E, Rennie DJ, Dudley RA. Relationship between discharge practices and intensive care unit in-hospital mortality performance: evidence of a discharge bias. Med Care. 2009;47(7):803-812.

41. Reineck LA, Pike F, Le TQ, Cicero BD, Iwashyna TJ, Kahn JM. Hospital factors associated with discharge bias in ICU performance measurement. Crit Care Med. 2014;42(5):1055-1064.

42. Diekema D, Arbefeville S, Boyken L, Kroeger J, Pfaller
M. The changing epidemiology of healthcare-associated candidemia over three decades. Diagn Microbiol Infect Dis. 2012;73(1):45-48.

43. Wallace DJ, Angus DC, Seymour CW, Barnato AE, Kahn JM. Critical care bed growth in the United States. A comparison of regional and national trends. Am J Respir Crit Care Med. 2015;191(4):410-416.

44. Seymour CW, Iwashyna TJ, Ehlenbach WJ, Wunsch H, Cooke CR. Hospital-level variation in the use of intensive care. Health Serv Res. 2012;47(5):2060-2080.

45. Sjoding MW, Prescott HC, Wunsch H, Iwashyna TJ, Cooke CR. Hospitals with the highest intensive care utilization provide lower quality pneumonia care to the elderly. Crit Care Med. 2015;43(6):1178-1186.

46. Checkley W, Martin GS, Brown SM, Chang SY, Dabbagh $\mathrm{O}$, Fremont RD, Girard TD, et al. Structure, process, and annual ICU mortality across 69 centers: United States Critical Illness and Injury Trials Group Critical Illness Outcomes Study. Crit Care Med. 2014;42(2):344-356.

47. Bingold TM, Lefering R, Zacharowski K, Meybohm P, Waydhas C, Rosenberger P, Scheller B. Individual Organ Failure and Concomitant Risk of Mortality Differs According to the Type of Admission to ICU - A Retrospective Study of SOFA Score of 23,795 Patients. PLoS One. 2015;10(8):e0134329. 